\title{
A BRIEF REVIEW OF THE BIOLOGY OF THE OCEANIC SQUID, SYMPLECTOTEUTHIS OUALANIENSIS (LESSON)
}

\author{
Richard EDWARd Young \\ Department of Oceanography, University of Hawaii, Honolulu, \\ HI 96822, U.S.A.
}

(Received 11 October 1974)

\begin{abstract}
Our current knowledge of the squid, Symplectoteuthis oualaniensis, one of the organisms utilized to a large extent during the Alpha Helix Kona Expedition, is briefly reviewed.
\end{abstract}

Symplectoteuthis oualaniensis (Lesson, 1830) is a member of the order Teuthoidea, the suborder Oegopsida and the family Ommastrephidae. Squids belonging to this family are among the largest and most numerous of the fast-swimming oceanic species. For example, Dosidicus gigas, the largest member of the family, reaches a total length (tip of tentacles to tip of tail) of about $4 \mathrm{~m}$ (Duncan, 1941) and has been observed to leap some distance out of the water (Roper \& Young, 1974); Todarodes pacificus has been captured in quantities of over 600,000 tons per year in Japan (Clarke, 1966).

The systematic position and, indeed, the identity of $S$. oualaniensis are in doubt. Wormuth (pers. comm.), relying on morphometrics, found that $S$. oualaniensis is more similar to Ommastrephes bartramii than to its supposed congener, $S$. luminosa. The feature that unites species of Symplectoteuthis is the fusion of the funnel and mantle locking cartilages. That is, these animals have the funnel permanently joined to the ventral wall of the mantle. On the other hand, in addition, to morphometric similarities, both $O$. bartramii and $S$. oualaniensis share an apparently unique feature: some of the tentacular suckers bear small finger-like projections which, presumably, are sensory organs (pers. obs.). The systematics of this family is being investigated by a number of workers (C. C. Lu, C. F. E. Roper, M. R. Clarke, J. H. Wormuth), and ultimately some generic rearrangement will probably be proposed (Wormuth, pers. comm.).

Clarke (1965) noted that two species of squids occur in the Pacific Ocean that can be identified as $S$. oualaniensis, and that these species have overlapping distributions. The larger species which attains a mantle length (ML) of $305 \mathrm{~mm}$ (females) can easily be distinguished from a slightly smaller species that grows to $250 \mathrm{~mm}$ ML (females) by the presence of spherical photophores forming an oval patch in the anterodorsal mantle musculature (Clarke, 1966); the smaller species lacks this patch. Only the large species with the dorsal patch occurs off Hawaii. Unfortunately the type specimen of $S$. oualaniensis has been lost, and even its size is unknown (Wormuth, pers. comm.) Since the species with the dorsal patch is more frequently collected (Wormuth, pers comm.), the odds favor it as being the true $S$. oualaniensis. The two species have never been fully compared in the litera- ture, and there is no available name for one of them. Until this problem is fully resolved, the species with the dorsal patch, for convenience sake, will be considered S. oualaniensis, and the smaller species without the dorsal photophores will be considered the undescribed species.

S. oualaniensis occurs throughout much of the Pacific and Indian Oceans. However, most captures have been made between about $30^{\circ}$ North latitude and $20^{\circ}$ South latitude (Wormuth, pers. comm.). The National Marine Fisheries Service in Honolulu has collected specimens of the undescribed species from $12^{\circ}$ North latitude to $4^{\circ}$ South latitude in the central Pacific Ocean (Burgess, 1970).

Little is known of the vertical distribution of $S$. oualaniensis. This squid can usually be seen at the surface on calm nights from a drifting ship where they are attracted by the ship's lights or, more likely, by the small fishes that swim beneath the lights. Most specimens are collected under such circumstances using dip nets or jigs. Indications of the day habitat are based on circumstantial evidence. The dark pigmentation on the dorsal surface of the mantle and head has a bluish cast. As far as is known, cephalopods that exhibit such color (e.g. Onykia carribaea, Tremoctopus violaceus) inhabit near-surface water during the day. The presence of young Symplectoteuthis spp. in the stomachs of day-feeding oceanic birds also suggests a shallow day habitat. Ashmole \& Ashmole (1967) in studying the feeding habitats of eight sea birds on Christmas Island in the Pacific Ocean found Symplectoteuthis spp. in $3497 \%$ of the birds examined depending on the species. Although some of these birds feed to some extent at night, others normally do not. The Ashmoles concluded that Symplectoteuthis spp. must be available at the surface in quantity during the day. Off Hawaii, Brown (1973) found that squid, mostly S. oualaniensis, comprised $54 \%$ of the diet by weight of the Sooty Tern and $38 \%$ of the diet of the Brown Noddy both of which feed primarily during the day.

$S$. oualaniensis, therefore, probably occupies nearsurface water both day and night; however, it is not necessarily restricted to these depths. Its close relatives in the genus Ommastrephes, while also common in near-surface water, have been photographed as deep as $1200 \mathrm{~m}$, and the tentacle of one specimen 
was caught in a reversing water bottle at nearly 1500 m (Clarke, 1966). Off Hawaii the related Hyaloteuthis pelagicus which occurs in the upper $100 \mathrm{~m}$ at night and is occasionally found in bird stomachs, has been taken in an opening-closing net in excess of $1800 \mathrm{~m}$ during the day (Young, 1975). Roper \& Young (1974) concluded that some members of the Ommastrephidae, while primarily surface living species, are capable of roaming through great depths of the ocean. The same behaviour may well occur in $S$. oualaniensis. Indeed, the peculiar extraocular photoreceptors in this squid led Young (1975) to suggest that one organ functions in near-surface waters while another functions at greater depths.

$S$. oualaniensis is a quick and powerful swimmer. This ability is apparent not only from its thick, muscular mantle but also by its near absence in trawls. Although common around Hawaii, this species, for the most part, easily avoids standard midwater trawls. Except for the anomalous capture of one large specimen that may have become entangled in the mesh of the net, the largest specimen taken during an intensive trawling program around Hawaii over the last 4 years was only $34 \mathrm{~mm}$ in mantle length. This specimen was taken in a $15 \mathrm{ft}$. (width of the net mouth) Isaacs-Kidd midwater trawl towed at 4 knots.

These powerful swimmers can readily propel themselves out of the water. Indeed, one young specimen was taken from the deck of our research ship; it probably flew aboard during the night. Ommastrephes bartramii, the close relative of $S$. oualaniensis, is commonly known as the flying squid, and it has been observed gliding above the surface of the ocean during the day (Arata, 1954; cf. Lane, 1957; Clark, 1966). On October 1, 1970, J. Andrews (pers. comm.) observed a school of flying squid from the $\mathrm{R} / \mathrm{V}$ Mahi at about $01^{\circ} \mathrm{N}$ and $180^{\circ} \mathrm{W}$. Although none of the squid were captured, the locality and the description of the animals strongly suggests that he observed one of the species of Symplectoteuthis. He was standing on the ship's bridge, about $15 \mathrm{ft}$. above sea level, when he saw about 20-24 squid 5-7 inches long leave the water under the bridge wing. The squid flew in a path parallel to the ship about $3 \mathrm{ft}$. above the calm sea, and they reentered the water just beyond the ship's bow. The speed of the ship was $10 \mathrm{kts}$., and the distance the squid traveled was estimated to be $150-200 \mathrm{ft}$. A jet of water trailing from the funnel could be seen during the first part of the flight. In spite of the small size of the spread fins, the animals seemed to glide for about half of the flight. There was no variation in their course during the flight, which lasted about 5 sec.

Squid apparently dart from the water when being pursued by a large predator (Clarke, 1966; Ashmole \& Ashmole, 1967). This behavioür must be common, for both the sooty tern and the brown noddy which feed heavily on squid around Hawaii do not enter the water to catch prey (Brown, 1973).

Information on predators of $S$. oualaniensis is meager. In addition to the birds mentioned above a number of fish are known to feed extensively on squid, but the identification and the size catagories of the squid consumed are unknown. Off Hawaii the skipjack tuna (Katsuwonus pelamis), and the yellowfin tuna (Thunnus albacares) and the wahoo (Acanthocybium solandrii) feed heavily on squid (Welsh, 1950) as probably does the bigeye tuna (Thunnus obesus) (cf. King \& Ikehara, 1956). Beaks of young squid, apparently $S$. oualaniensis, have been found in the stomachs of blue marlin (Makaira nigricans), and $\mathrm{T}$. Clarke (1971) found a variety of squid beaks in the stomach of the scalloped hammerhead shark (Sphyrna lewini) off Hawaii. On the other hand, the mahimahi (Coryphaena hippurus) and the bonito (Euthynnus yaito) in Hawaiian water are only occasional predators on squid (Welsh, 1950). Although the night-feeding porpoises Stenella longirostris hawaiiensis and Stenella attenuata feed heavily on squid, they do not eat $S$. oualaniensis (Shomura \& Hida, 1965; Norris \& Dohl, in preparation).

Around the night light $S$. oualaniensis can be seen to attack and frequently capture lanternfish (Myctophidae) which have migrated to the surface from deep water. Stomachs of $10 \mathrm{~S}$. oualaniensis were examined: 9 were captured around the night light and one came from a midwater trawl. All specimens were between 130 and $185 \mathrm{~mm}$ ML. Stomach contents included amphipods, crab megalopa, small shrimps, stomatopod larvae, crab zoea, large copepods, euphausiids, and enoploteuthid squids, but primarily fishes. One stomach contained the remains of 14 fish. Most of the small crustaceans probably came from the stomachs of devoured fish. In one squid stomach a crab megalopa, a euphausiid and a small shrimp were neatly encased in a membrane which must have been the remnant of a fish stomach. The enoploteuthid squid, however, were too large to have come from the fish. This small and biased sample suggests that $S$. oualaniensis in this size range feeds primarily on small fish and occasionally eats other squids.

$S$. oualaniensis is abundant over vast areas of the pacific and Indian Oceans. While this species is fished commercially off Okinawa (Sasaki, 1929; Clarke, 1966), Clarke (1966) has indicated that it remains a largely untapped resource of the open ocean. Its palatibility can be vouched for. However, in spite of its abundance and its commercial potential, little is known of its biology. As with the other chief experimental organism of the Kona Expedition of the R/V Alpha Helix, we are at an unusual stage where we know more about the biochemistry of the animal than we do about the organism as a whole. Clearly, much more work remains before we have a complete picture of the ecology of this fascinating animal.

\section{REFERENCES}

Arata G., (1954) A note on the flying behaviour of certain squids. Nautilus $68,1-3$.

Ashmole N. \& ASHMOLE M. (1967) Comparative feeding ecology of sea birds of a tropical oceanic island. Bull. Peabody Mus. Nat. Hist. 24, 1-131.

Brown W. (1973) The breeding biology of sooty terns and brown noddies on Manana or Rabbit Island, Oahu, Hawaii. Ph.D. dissertation

Burgess L. A. (1970) A report on the Cephalopoda of the Hawaii area. Report of the director, National Marine Fisheries Service, Hawaii branch.

Clarke M. (1965) Large light organs on the dorsal surfaces of the squids, Ommastrephes pteropus, Symplectoteuthis oualaniensis and Dosidicus gigas. Proc. malac. Soc. Lond. 36. $319-321$.

Clarke M. (1966) A review of the systematics and ecology of oceanic squids. Adv. mar. Biol., 4, 91-300. 
Clarke T. (1971) The ecology of the scalloped hammerhead shark, Sphyrna lewini in Hawaii. Pacif. Sci. 25(2), 133144.

DunCan D. (1941) Fishing giants of the Humboldt. Natn. Geogr. Mag. 79, 373-400.

KING J. E. \& IkEhara I. I. (1956) Comparative study of food of bigeye and yellowfin tuna in the central Pacific. Fishery Bull. Fish Wildl. Serv. U.S. 57, 61-85.

LANE, F. (1957) The Kingdom of the Octopus, 287 pp. Jarrolds, London.

Lesson R. P. (1830) Mollusques. Voyage dans la Coquille, 2. 239-246.

Longhurst A. (1969) Pelagic invertebrate resources of the California Current. Cal. COFI Rep. 13, 60-62.
NorRIS K. \& DoHL T. (Monograph on porpoises). (In preparation.)

ROPER C. \& Young R. (1974) The vertical distribution of pelagic cephalopods. Smithson. Contr. Zool. (In press). ShomURA R. \& HidA T. (1965) Stomach contents of a dolphin caught in Hawaiian waters. J. Mammal. 46(3), 500501.

SASAKI M. (1929) A monograph of the dibranchiate cephalopods of the Japanese and adjacent waters. J. Fac. Agric. Hokkaido Imp. Univ. 20(10), 1-357.

WeLSH J. (1950) A preliminary study of food and feeding habits of Hawaiian kawakawa, mahimahi, ono, aku, and ahi. Fish Game Spec. Bull. Hawaii 2, 1-26.

YounG R. (1975) Aspects of the ecology of pelagic cephalopods off Oahu, Hawaii. (In preparation.) 